\title{
Clinical Characteristics of Patients with Untreated Achalasia
}

\author{
Han Ho Jeon, ${ }^{1}$ Jie-Hyun Kim, ${ }^{2}$ Young Hoon Youn, ${ }^{2}$ Hyojin Park, ${ }^{2 *}$ and Jeffrey L Conklin ${ }^{3}$ \\ ${ }^{I}$ Division of Gastroenterology, Department of Internal Medicine, National Health Insurance Service Ilsan Hospital, Ilsan, Gyeonggi-do, Korea; \\ ${ }^{2}$ Department of Internal Medicine, Gangnam Severance Hospital, Yonsei University College of Medicine, Seoul, Korea; and ${ }^{3}$ Division of Digestive \\ Diseases, University of California Los Angeles, Los Angeles, CA, USA
}

\section{Background/Aims}

Patients with untreated achalasia frequently complain of heartburn and regurgitation. The diagnosis of achalasia might be delayed because these symptoms are misinterpreted as gastroesophageal reflux. We aim to evaluate the clinical, radiologic, and manometric findings in patient with untreated achalasia.

\section{Methods}

The records of patients diagnosed with primary achalasia between July 2004 and January 2012 at Gangnam Severance Hospital, Seoul, Korea were evaluated. We reviewed their clinical history and the findings of barium esophagogram, upper gastrointestinal endoscopy, and esophageal transit scintigraphy. We also compared the clinical, radiologic, and manometric findings of patients according to heartburn symptoms and proton pump inhibitor use.

\section{Results}

Our study included a total of 64 patients with a median age of 44.5 (interquartile range, 31.5-54.0). The median duration of symptoms was 23.5 (interquartile range, 5.3-57.0) months. Sixty-four patients (100\%) had dysphagia, 49 (76.6\%) had regurgitation, $35(54.7 \%)$ had chest pain, and 38 (59.4\%) had heartburn. Typical clinical features of gastroesophageal reflux disease (GERD) such as regurgitation, heartburn, and chest pain were observed in more than $50 \%$ of achalasia patients. Proton pump inhibitors were prescribed for 16 patients (25\%) on the assumption that they had GERD. Patients with heartburn were more likely to experience weight loss $(P=0.009)$, regurgitation $(P=0.001)$, or chest pain $(P=0.019)$.

\section{Conclusions}

Heartburn, regurgitation, and chest pain were commonly observed in patients with untreated achalasia. Therefore, these findings suggest that achalasia should be suspected in patients with refractory GERD.

(J Neurogastroenterol Motil 2017;23:378-384)

\section{Key Words}

Diagnosis; Esophageal achalasia; Gastroesophageal reflux

Received: October 13, 2016 Revised: January 3, 2017 Accepted: January 22, 2017

(.) This is an Open Access article distributed under the terms of the Creative Commons Attribution Non-Commercial License (http://creativecommons. org/licenses/by-nc/4.0) which permits unrestricted non-commercial use, distribution, and reproduction in any medium, provided the original work is properly cited.

${ }^{*}$ Correspondence: Hyojin Park, MD, PhD Institute of Gastroenterology, Department of Internal medicine, Gangnam Severance Hospital, Yonsei University College of Medicine, 211 Eonju-ro, Gangnam-gu, Seoul 06273, Korea Tel: +82-2-2019-3318, Fax: +82-2-3463-3882, E-mail: HJPARK21@yuhs.ac 


\section{Introduction}

Achalasia is an uncommon primary esophageal motor disorder that is defined by lack of peristalsis in the smooth muscle esophagus and failed or insufficient relaxation of the lower esophageal sphincter (LES) in response to swallowing. ${ }^{1}$

Frequently, gastroenterologists in referral centers see patients with achalasia who were previously diagnosed with gastroesophageal reflux disease (GERD) based on symptoms, but who did not respond to proton pump inhibitor (PPI) treatment. This is likely because while both disorders can present with similar symptoms, GERD is more common, making it the default diagnosis for a practitioner with limited awareness and knowledge of achalasia. In addition, achalasia has an insidious onset and progresses gradually, giving the illusion that it is a chronic but stable condition. Therefore, patients with achalasia typically experience symptoms for years before diagnosis. A previous report showed that the mean duration of symptoms prior to diagnosis was 4.7 years in patients with newly diagnosed achalasia. ${ }^{2}$ The delay in diagnosis was mainly because typical symptoms like heartburn and regurgitation were misinterpreted as GERD. Stasis of food with acidic content is frequently misunderstood as the acid regurgitation of GERD, and fermentation can cause heartburn. This leads many patients to being treated for GERD well before the diagnosis of achalasia is made. ${ }^{3}$ Having said this, it is not known how often the presence of symptoms erroneously leads to treatment with a PPI on the assumption that GERD is present.

The aim of this study is to evaluate the clinical, radiologic, and manometric findings of our patients with untreated achalasia.

\section{Materials and Methods}

\section{Patients}

The clinical records of patients with achalasia at Gangnam Severance Hospital in Seoul, Korea, between July 2004 and January 2012, were retrospectively collected. The diagnosis of achalasia was based on the results of clinical evaluation with barium esophagram, endoscopy, esophageal transit scintigraphy (ETS), and esophageal manometry. None of the patients had underwent previous endoscopic treatment (botulinum toxin injection or pneumatic dilatation) or surgical myotomy at the time of their evaluation for this study.

This was a retrospective study from a prospectively collected database. The data were stored in paper form. Questionnaires (in- cluding dysphagia grade and the Eckardt score) were updated at the time of diagnosis. In particular, we checked whether patients were taking PPI because their primary physician had presumed their symptoms were caused by refractory GERD. The definition of refractory GERD remains controversial. ${ }^{4-6}$ Refractory GERD was defined as the persistence of symptoms that do not respond to standard dose of PPI once daily during a treatment period of at least 8 weeks. Patients with achalasia were excluded if they had a previous treatment history of botulinum toxin injection, pneumatic dilatation or surgical myotomy. This study had Institutional Review Board approval of Gangnam Severance Hospital.

\section{Symptom Evaluation}

Patients were assessed using the Eckardt score ${ }^{7}$ and dysphagia grade. The Eckardt score is derived from several symptom scores for dysphagia, regurgitation, and chest pain ( 0 , absent; 1 , occasional; 2 , daily; and 3 , each meal), and weight loss ( 0 , no weight loss; 1, < $5 \mathrm{~kg} ; 2,5-10 \mathrm{~kg}$; and 3, $>10 \mathrm{~kg}$ ). The scores from each symptom are summed to make a total score that ranges from 0 to 12 points. The heartburn was categorized into 4 groups according to symptom frequency ( 0 , absent; 1 , occasional; 2 , daily; and 3, each meal). The duration of symptoms was also recorded. The dysphagia grade was categorized into five groups according to the severity of the dysphagia ( 1 indicates dysphagia to meat; 2 , to rice; 3 , to semisolid diet; 4 , to a liquid diet; and 5 to water).

\section{Esophagram}

Esophagram was performed in the erect anteroposterior projection, as well as the erect left posterior and anterior oblique fluoroscopic projections (Shimavision 2000HG; Shimadzu, Kyoto, Japan). The shape of the esophagus, its maximum diameter, narrowing at the esophagogastric junction, and the presence of diverticula were recorded. Two gastrointestinal radiologists reviewed all measurements, and a consensus was reached.

\section{Esophageal Transit Scintigraphy}

ETS was performed with technetium-99m after overnight fasting. All ETS images were acquired using a gamma camera (Genesys Vertex; Adac Laboratories, CA, USA) and an anterior scan with the patient in the erect position. The time-radioactivity curve was made using the method described in a previous study. ${ }^{8}$ The time required for radioactivity in the esophagus to reach half of the maximum was defined as the half time $\left(T_{1 / 2}\right)$. The residual fraction of maximum radioactivity in the esophagus at 30 seconds was defined as $R_{30}(\%)$. 


\section{Esophageal Manometry}

Esophageal manometry was performed using an eight-channel water perfusion system from Synectics Medical Carsen Group (Washington, USA) from 2002 to 2010. After 2011, esophageal manometry was performed by high-resolution manometry (HRM) with a 21-channel manometric assembly from Sierra Scientific Instruments (Los Angeles, CA, USA). The data were digitized and displayed, stored, and analyzed using Mano View analysis software from Sierra Scientific Instruments. Each manometry procedure was performed as previously described. ${ }^{8}$

Achalasia was diagnosed by conventional manometry when there was a lack of peristalsis in the smooth muscle esophagus and when failed or insufficient relaxation of the LES was present. Achalasia was diagnosed by HRM when the integrated relaxation pressure was 15 or greater and there was no peristalsis in the smooth muscle of the esophagus. Of the total number of patients in our study, only 47 patients had undergone esophageal manometry tests, 39 patients of which were tested by conventional manometry, and 8 patients by HRM.

\section{Statistical Methods}

Frequency, percentage, and median (interquartile range) were used as descriptive statistics. Chi-square tests or Fisher's exact test were used to compare categorical variables. Continuous variables are presented as medians and were compared using a Mann-Whitney $\mathrm{U}$ test. Differences were considered significant at a $P$-value of less than 0.05. All statistical analysis was performed using the Statistical Package for the Social Sciences (SPSS) 18.0 for Windows (IBM Corp, Armonk, NY, USA).

\section{Results}

\section{Patient Characteristics}

This study included a total of 64 patients (36 female and 28 male) with primary achalasia. Clinical, radiographic, and manometric data of the patients are provided in Table 1 . All 64 patients had dysphagia, with the median dysphagia grade being 3 (2-4), and the median duration of symptoms was 23.5 (interquartile range, 5.357.0) months. Other symptoms at the time of presentation were regurgitation (76.6\%), chest pain $(54.7 \%)$, heartburn (59.4\%), and weight loss (68.7\%). The median Eckardt score was 5 (3-7). At the time of referral to our center, 16 patients $(25.0 \%)$ were taking a PPI on the assumption by the referring physician that refractory
Table 1. Baseline Patient Characteristics

\begin{tabular}{|c|c|}
\hline Total patients & 64 \\
\hline Age (median [IQR], yr) & $44.5(31.5-54.0)$ \\
\hline Duration of symptoms (median [IQR], mo) & $23.5(5.3-57.0)$ \\
\hline Sex $($ female/male, $n)$ & $36(56.3 \%) / 28(43.7 \%)$ \\
\hline \multicolumn{2}{|l|}{ Weight loss (n) } \\
\hline $0 \mathrm{~kg}$ & $20(31.3 \%)$ \\
\hline$<5 \mathrm{~kg}$ & $25(39.1 \%)$ \\
\hline $5-10 \mathrm{~kg}$ & $17(26.6 \%)$ \\
\hline$>10 \mathrm{~kg}$ & $2(3.0 \%)$ \\
\hline \multicolumn{2}{|l|}{ Dysphagia (n) } \\
\hline No & $0(0.0 \%)$ \\
\hline Occasionally & $15(23.4 \%)$ \\
\hline Every day & $21(32.8 \%)$ \\
\hline Several times/day & $28(43.8 \%)$ \\
\hline \multicolumn{2}{|l|}{ Regurgitation (n) } \\
\hline No & $15(23.4 \%)$ \\
\hline Occasionally & $26(40.7 \%)$ \\
\hline Every day & $18(28.1 \%)$ \\
\hline Several times/day & $5(7.8 \%)$ \\
\hline \multicolumn{2}{|l|}{ Chest pain (n) } \\
\hline No & $29(45.3 \%)$ \\
\hline Occasionally & $24(37.5 \%)$ \\
\hline Every day & $7(10.9 \%)$ \\
\hline Several times/day & $4(6.3 \%)$ \\
\hline \multicolumn{2}{|l|}{ Heartburn (n) } \\
\hline No & $26(40.6 \%)$ \\
\hline Occasionally & $27(42.2 \%)$ \\
\hline Every day & $9(14.1 \%)$ \\
\hline Several times/day & $2(3.1 \%)$ \\
\hline \multicolumn{2}{|l|}{ Dysphagia grade (n) } \\
\hline Meat & $4(6.3 \%)$ \\
\hline Rice & $21(32.8 \%)$ \\
\hline Semisolid & $17(26.6 \%)$ \\
\hline Liquid & $15(23.4 \%)$ \\
\hline All & $7(10.9 \%)$ \\
\hline Eckardt score (median [IQR]) & $5(3-7)$ \\
\hline Proton pump inhibitor use (n) & $16(25.0 \%)$ \\
\hline \multicolumn{2}{|l|}{ Esophagram (median [IQR], mm) } \\
\hline Maximum diameter of the esophageal body & $44(38-52)$ \\
\hline \multicolumn{2}{|l|}{ Manometry $^{\mathrm{a}}($ median $[\mathrm{IQR}], \mathrm{mmHg})$} \\
\hline LES pressure of conventional manometry & $44.3(28.1-71.1)$ \\
\hline LES pressure of high-resolution manometry & $37.1(22.8-64.2)$ \\
\hline \multicolumn{2}{|c|}{ Esophageal scan ${ }^{\mathrm{b}}$} \\
\hline$T_{1 / 2}($ median $[\mathrm{IQR}], \min )$ & $22.5(4.7-503.8)$ \\
\hline$R_{30}(\operatorname{median}[\mathrm{IQR}], \%)$ & $64.0(41.5-83.5)$ \\
\hline
\end{tabular}

${ }^{a}$ Only 47 patients were tested by esophageal manometry (39 conventional manometry and 8 high-resolution manometry).

${ }^{\mathrm{b}}$ Fifty-seven patients were examined by esophageal scan.

IQR, interquartile range; LES, lower esophageal sphincter; $T_{1 / 2}$, half time of esophageal transit scintigraphy; $R_{30}$, the residual fraction of maximum radioactivity in the distal esophagus after 30 seconds. 
GERD was the cause of their symptoms. Persistence of symptoms and poor response despite PPI therapy, and/or endoscopic findings not consistent with symptoms were the main indications for referral to our tertiary care center. Endoscopy was performed in all patients. No patients had Barrett's esophagus, stricture, or cancer.

Sixty-one patients (95.3\%) underwent barium esophagram. The other 3 patients could not hold a sufficient mouthful of barium to ensure adequate swallow volumes. The median maximum diameter of the esophageal body was $44 \mathrm{~mm}$ (38-52). A dilated and tortuous esophagus was present in 6 patients (9.4\%). Diverticulae were present in 2 patients (3.1\%).

Forty-seven patients were diagnosed by esophageal manometry. Thirty-nine patients who received conventional manometry had a median LES pressure of $44.3 \mathrm{mmHg}$ (28.1-71.1). Eight patients who received HRM had a median resting LES pressure of 37.1
$\mathrm{mmHg}$ (22.8-64.2). The other 17 patients were diagnosed by barium esophagram, either because they could not tolerate the manometry catheter or because the catheter could not be placed due to esophageal dilatation and tortuosity of the lower esophagus.

Fifty-seven patients received ETS. The median $T_{1 / 2}$ for esophageal emptying was 22.5 (4.7-503.8) minutes. The median $R_{30}$ was $64 \%(41.5-83.5 \%)$.

\section{Comparison of Clinical, Radiographic, and Manometric Findings in Relation to Heartburn Symptoms}

Comparison of clinical, radiographic, and manometric findings according to the presence or absence of heartburn symptoms showed that age, sex, duration of symptoms, dysphagia, dysphagia grade, and PPI use were similar between the 2 groups (Table 2). Patients with heartburn symptoms were more likely to exhibit

Table 2. Comparison of Clinical, Radiographic, and Manometric Profiles in Relation to Heartburn Symptoms

\begin{tabular}{|c|c|c|c|}
\hline & $\begin{array}{l}\text { Heartburn symptoms } \\
\qquad(\mathrm{n}=38)\end{array}$ & $\begin{array}{l}\text { No heartburn symptoms } \\
\qquad(\mathrm{n}=26)\end{array}$ & $P$-value \\
\hline Age (median [IQR], yr) & $41.0(33.8-54.3)$ & $47.0(30.8-53.5)$ & 0.848 \\
\hline Sex (female/male, $n)$ & $19(50.0 \%) / 19(50.0 \%)$ & $17(65.4 \%) / 9(34.6 \%)$ & 0.223 \\
\hline Duration of symptoms (median [IQR], mo) & $17.5(5.0-69.0)$ & $30(5.5-54.0)$ & 0.768 \\
\hline \multicolumn{4}{|l|}{ Weight loss (n) } \\
\hline$<5 \mathrm{~kg} / \geq 5 \mathrm{~kg}$ & $22(57.9 \%) / 16(42.1 \%)$ & $23(88.5 \%) / 3(11.5 \%)$ & 0.009 \\
\hline \multicolumn{4}{|l|}{ Dysphagia (n) } \\
\hline$<$ Occasionally $/ \geq$ every day & $7(18.4 \%) / 31(81.6 \%)$ & $8(30.8 \%) / 18(69.2 \%)$ & 0.252 \\
\hline \multicolumn{4}{|l|}{ Regurgitation (n) } \\
\hline$<$ Occasionally/ $\geq$ every day & $18(47.4 \%) / 20(52.6 \%)$ & $23(88.5 \%) / 3(11.5 \%)$ & 0.001 \\
\hline \multicolumn{4}{|l|}{ Chest pain (n) } \\
\hline$<$ Occasionally $/ \geq$ every day & $28(73.7 \%) / 10(26.3 \%)$ & $25(96.2 \%) / 1(3.8 \%)$ & 0.019 \\
\hline Proton pump inhibitor use (n) & $12(31.6 \%)$ & $4(15.4 \%)$ & 0.142 \\
\hline \multicolumn{4}{|l|}{ Dysphagia grade (n) } \\
\hline $1-2 / 3-5$ & $14(36.8 \%) / 24(63.2 \%)$ & $11(42.3 \%) / 15(57.7 \%)$ & 0.660 \\
\hline Eckardt score (median [IQR]) & $6(4.0-7.3)$ & $3(2.0-4.3)$ & $<0.001$ \\
\hline \multicolumn{4}{|l|}{ Esophagram (median [IQR], mm) } \\
\hline Maximum diameter of the esophageal body & $46.0(38.0-54.0)$ & $40.0(36.0-51.2)$ & 0.206 \\
\hline \multicolumn{4}{|l|}{ Conventional manometry } \\
\hline LES pressure (median $[\mathrm{IQR}], \mathrm{mmHg})^{\mathrm{a}}$ & $42.7(25.8-57.8)$ & $57.4(32.3-109.2)$ & 0.175 \\
\hline \multicolumn{4}{|l|}{ High-resolution manometry } \\
\hline LES pressure (median [IQR], mmHg) & $43.2(17-43.2)$ & $31(23.6-77)$ & 0.881 \\
\hline \multicolumn{4}{|l|}{ Esophageal scan ${ }^{c}$} \\
\hline$T_{1 / 2}(\operatorname{median}[\mathrm{IQR}], \mathrm{min})$ & $27.9(4.3-499.5)$ & $17.8(4.4-1144)$ & 0.949 \\
\hline$R_{30}($ median $[\mathrm{IQR}], \%)$ & $60(45-76)$ & $66(36.8-87.3)$ & 0.558 \\
\hline
\end{tabular}

${ }^{a}$ Thirty-nine patients were examined by conventional manometry.

${ }^{\mathrm{b}}$ Eight patients were examined by high-resolution manometry.

${ }^{c}$ Fifty-seven patients were examined by esophageal scan.

IQR, interquartile range; LES, lower esophageal sphincter; $T_{12}$, half time of esophageal transit scintigraphy; $R_{30}$, the residual fraction of maximum radioactivity in the distal esophagus after 30 seconds. 
weight loss $\geq 5 \mathrm{~kg}(P=0.009)$, daily regurgitation $(P=0.001)$, and daily chest pain $(P=0.019)$. They also had a higher Eckardt score $(P<0.001)$. However, there were no statistically significant differences between the groups with regard to other factors.

\section{Comparison of Clinical, Radiographic, and Manometric Findings in Relation to Proton Pump Inhibitor Use}

We compared the clinical, radiographic, and manometric findings in relation to erroneous GERD diagnosis based on the use of PPI on the assumption by the referring physician as refractory GERD (Table 3). The PPI-treated group was defined as standard dose of PPI once daily treatment for at least 8 weeks. There were no statistically significant differences between the groups for any of the variables tested, including duration of symptoms.

\section{Discussion}

The major findings of our study in patients with untreated achalasia are as follows. First, dysphagia was the most common complaint, although regurgitation and heartburn were also frequently present. The prevalence of heartburn in our patients with achalasia was $59.4 \%$, which is higher than that reported elsewhere. $^{9-11}$ It is generally thought that the diagnosis of GERD can be reliably made on the basis of clinical symptoms: if a patient has heartburn or regurgitation it is assumed that acid reflux is present, and therefore a PPI is prescribed. However, symptoms are less sensitive and specific than commonly believed. A previous study showed that symptoms alone cannot distinguish real GERD from

Table 3. Comparison of Clinical, Radiographic, and Manometric Profiles in Relation to Proton Pump Inhibitor Use

\begin{tabular}{|c|c|c|c|}
\hline & $\begin{array}{l}\text { PPI-treated group }{ }^{a} \\
\qquad(\mathrm{n}=16)\end{array}$ & $\begin{array}{l}\text { PPI untreated group } \\
\qquad(\mathrm{n}=48)\end{array}$ & $P$-value \\
\hline Age (median [IQR], yr) & $41.5(35.3-56.3)$ & $45.5(31-53.8)$ & 0.614 \\
\hline Sex (female/male, n [\%]) & $6(37.5 \%) / 10(62.5 \%)$ & $30(62.5 \%) / 18(37.5 \%)$ & 0.080 \\
\hline Duration of symptoms (median [IQR], mo) & $11(6.26-33)$ & $24(5-90)$ & 0.469 \\
\hline \multicolumn{4}{|l|}{ Weight loss (n) } \\
\hline$<5 \mathrm{~kg} / \geq 5 \mathrm{~kg}$ & $12(75 \%) / 4(25 \%)$ & $33(68.8 \%) / 15(31.2 \%)$ & 0.636 \\
\hline \multicolumn{4}{|l|}{ Dysphagia } \\
\hline$<$ Occasionally $/ \geq$ every day & $4(25 \%) / 12(75 \%)$ & $11(22.9 \%) / 37(77.1 \%)$ & 0.865 \\
\hline \multicolumn{4}{|l|}{ Regurgitation $n)$} \\
\hline$<$ Occasionally $/ \geq$ every day & $10(62.5 \%) / 6(37.5 \%)$ & $31(64.6 \%) / 17(35.4 \%)$ & 0.880 \\
\hline \multicolumn{4}{|l|}{ Chest pain (n) } \\
\hline$<$ Occasionally $/ \geq$ every day & $12(75 \%) / 4(25 \%)$ & $41(85.4 \%) / 7(14.6 \%)$ & 0.339 \\
\hline \multicolumn{4}{|l|}{ Heart burn $(n)$} \\
\hline$<$ Occasionally $/ \geq$ every day & $12(75 \%) / 4(25 \%)$ & $41(85.4 \%) / 7(14.6 \%)$ & 0.339 \\
\hline \multicolumn{4}{|l|}{ Dysphagia grade (n) } \\
\hline $1-2 / 3-5$ & $6(37.5 \%) / 10(62.5 \%)$ & $19(39.6 \%) / 29(60.4 \%)$ & 0.882 \\
\hline Eckardt score (median [IQR]) & $5.5(4-7.8)$ & $4.5(3-7)$ & 0.407 \\
\hline \multicolumn{4}{|l|}{ Esophagram (median [IQR], mm) } \\
\hline Maximum diameter of the esophageal body & $44.0(38.1-51.5)$ & $44.0(36.3-53)$ & 0.694 \\
\hline \multicolumn{4}{|l|}{ Conventional manometry } \\
\hline LES pressure (median [IQR], mmHg) & $42.7(28.1-73)$ & $45.0(26.9-69)$ & 0.888 \\
\hline \multicolumn{4}{|l|}{ High-resolution manometry } \\
\hline LES pressure (median $[\mathrm{IQR}], \mathrm{mmHg})^{\mathrm{c}}$ & $25.2(22-25.2)$ & $59(24-81)$ & 0.393 \\
\hline \multicolumn{4}{|l|}{ Esophageal scan $^{\mathrm{d}}$} \\
\hline$T_{1 / 2}($ median $[\mathrm{IQR}], \mathrm{min})$ & $12.3(5-140.4)$ & $22.6(4.3-948)$ & 0.270 \\
\hline$R_{30}(\operatorname{median}[\mathrm{IQR}], \%)$ & $58(38.8-77.8)$ & $65(41-87)$ & 0.572 \\
\hline
\end{tabular}

${ }^{\mathrm{a}}$ Standard dose proton pump inhibitor (PPI) once daily treatment during at least 8 weeks.

${ }^{\text {b}}$ Thirty-nine patients were examined by conventional manometry.

${ }^{\mathrm{c}}$ Eight patients were examined by high-resolution manometry.

${ }^{\mathrm{d}}$ Fifty-seven patients were examined by esophageal scan.

IQR, interquartile range; LES, lower esophageal sphincter; $T_{1 / 2}$, half time of esophageal transit scintigraphy; $R_{30}$, the residual fraction of maximum radioactivity in the distal esophagus after 30 seconds. 
other disorders. ${ }^{12}$ Patients with achalasia frequently complain of regurgitation and heartburn. In untreated patients, postprandial stasis and fermentation of food in the esophagus due to impaired esophageal emptying are thought to cause these symptoms. ${ }^{13-15}$ Additionally, dysphagia is frequently reported by patients with GERD. ${ }^{16}$ Therefore, achalasia can be erroneously diagnosed as GERD.

Second, achalasia patients with heartburn were more likely to experience weight loss, regurgitation, and chest pain. These patients might have more prominent postprandial stasis, fermentation of food and poor esophageal clearance, which cause pseudo-gastroesophageal reflux. ${ }^{13-15,17}$ A previous study showed a high prevalence of heartburn in achalasia patients, although objective evidence of GERD was weak. ${ }^{18}$ Another study suggested that other processes such as esophageal muscle spasm, ischemia, or esophageal distension might account for the heartburn and chest pain in patients with achalasia. ${ }^{19}$ Weight loss of between 5 and $10 \mathrm{~kg}$ occurs in many, but not all, achalasia patients. Our patients with heartburn were more likely to have weight loss of $\geq 5 \mathrm{~kg}$ than those without heartburn. Perhaps it is the regurgitation and chest pain that are more likely in patients with heartburn, which have a negative influence on the dietary intake of achalasia patients.

Third, the median duration of symptoms at the time of diagnosis of achalasia was 23.5 months. This is different from the findings of several previous studies in which the mean duration of symptoms at diagnosis was greater than 4 years. ${ }^{2,20}$ Achalasia has an insidious onset and disease progression is gradual, therefore patients typically experience symptoms for years prior to seeking medical care. Previous studies concluded that the delay in diagnosis was due to misinterpretation as GERD based on typical clinical findings of achalasia. Many patients are treated for GERD before the diagnosis of achalasia ${ }^{3,17}$; indeed, $25 \%$ of patients in this study were treated with PPIs for relief of symptoms. However, the duration of symptoms was shorter in our patient population than in other studies, and misdiagnosis as GERD was not a major factor in the delay of diagnosis of achalasia. There are several possible reasons for these differences. Endoscopy is inexpensive and widely available in Korea, even in primary care clinics. Because endoscopy is available in almost all regions of Korea, other diseases such as GERD or esophageal cancer can be excluded on endoscopy. Most patients who present with heartburn, epigastric pain, regurgitation, and dysphagia initially undergo an endoscopic examination. Furthermore, the medical care and services, including manometry, that are provided by tertiary hospitals are very accessible in almost all areas of Korea. Consequently, manometry was used early to evaluate patients with symptoms who had not responded to PPI therapy and had non-specific findings on endoscopy. Our findings support the medical statement of the American Gastroenterological Association that manometry should be used to evaluate patients with suspected GERD who do not respond to PPI therapy and have normal findings on endoscopy. ${ }^{21}$

There are some limitations in this study. First, it was a retrospective study in a single tertiary hospital. Second, the sample size was relatively small because achalasia is rare, which makes it difficult to enroll a large population. Third, this study used univariate analysis.

In conclusion, the clinical presentation of patients with untreated achalasia can show overlap with those of patients with GERD. Therefore, these findings suggest that achalasia should be suspected in patients with refractory GERD.

\section{Financial support: None.}

\section{Conflicts of interest: None.}

Author contributions: All authors contributed to this report and have fully approved its contents. Han Ho Jeon performed the data analysis and wrote the manuscript; Hyojin Park had original idea on this subject, performed the data analysis, and wrote the manuscript; and Jie-Hyun Kim, Young Hoon Youn, and Jeffrey L Conklin reviewed the manuscript critically.

\section{References}

1. Cohen S. Motor disorders of the esophagus. N Engl J Med 1979;301: 184-192.

2. Eckardt VF, Kohne U, Junginger T, Westermeier T. Risk factors for diagnostic delay in achalasia. Dig Dis Sci 1997;42:580-585.

3. Howard PJ, Maher L, Pryde A, Cameron EW, Heading RC. Five year prospective study of the incidence, clinical features, and diagnosis of achalasia in Edinburgh. Gut 1992;33:1011-1015.

4. Fass R, Sifrim D. Management of heartburn not responding to proton pump inhibitors. Gut 2009;58:295-309.

5. Targownik LE, Metge C, Roos L, Leung S. The prevalence of and the clinical and demographic characteristics associated with high-intensity proton pump inhibitor use. Am J Gastroenterol 2007;102:942-950.

6. Dickman R, Maradey-Romero C, Gingold-Belfer R, Fass R. Unmet needs in the treatment of gastroesophageal reflux disease. J Neurogastroenterol Motil 2015;21:309-319.

7. Eckardt VF. Clinical presentations and complications of achalasia. Gastrointest Endosc Clin N Am 2001;11:281-292, vi.

8. Jeon HH, Youn YH, Rhee K, Kim JH, Park H, Conklin JL. For patients with primary achalasia the clinical success of pneumatic balloon dilatation can be predicted from the residual fraction of radionuclide dur- 
ing esophageal transit scintigraphy. Dig Dis Sci 2014;59:375-382.

9. Blam ME, Delfyett W, Levine MS, Metz DC, Katzka DA. Achalasia: a disease of varied and subtle symptoms that do not correlate with radiographic findings. Am J Gastroenterol 2002;97:1916-1923.

10. Vela MF, Vaezi MF. Cost-assessment of alternative management strategies for achalasia. Expert Opin Pharmacother 2003;4:2019-2025.

11. Fisichella PM, Raz D, Palazzo F, Niponmick I, Patti MG. Clinical, radiological, and manometric profile in 145 patients with untreated achalasia. World J Surg 2008;32:1974-1979.

12. Patti MG, Diener U, Tamburini A, Molena D, Way LW. Role of esophageal function tests in diagnosis of gastroesophageal reflux disease. Dig Dis Sci 2001;46:597-602.

13. Patti MG, Arcerito M, Tong J, et al. Importance of preoperative and postoperative $\mathrm{pH}$ monitoring in patients with esophageal achalasia. J Gastrointest Surg 1997;1:505-510.

14. Crookes PF, Corkill S, DeMeester TR. Gastroesophageal reflux in achalasia. When is reflux really reflux? Dig Dis Sci 1997;42:1354-1361.

15. Smart HL, Foster PN, Evans DF, Slevin B, Atkinson M. Twenty four hour oesophageal acidity in achalasia before and after pneumatic dilatation. Gut 1987;28:883-887.

16. Kahrilas PJ. Clinical practice. Gastroesophageal reflux disease. N Engl J Med 2008;359:1700-1707.

17. Rosenzweig S, Traube M. The diagnosis and misdiagnosis of achalasia. A study of 25 consecutive patients. J Clin Gastroenterol 1989;11:147153.

18. Ponce J, Ortiz V, Maroto N, Ponce M, Bustamante M, Garrigues V. High prevalence of heartburn and low acid sensitivity in patients with idiopathic achalasia. Dig Dis Sci 2011;56:773-776.

19. Traube M. The acid achalasia association. J Clin Gastroenterol 2002;34:382-384.

20. Fellows IW, Ogilvie AL, Atkinson M. Pneumatic dilatation in achalasia. Gut 1983;24:1020-1023.

21. Kahrilas PJ, Shaheen NJ, Vaezi MF, et al. American gastroenterological association medical position statement on the management of gastroesophageal reflux disease. Gastroenterology 2008;135:1383-1391, e1-e5. 